\title{
Internet access and its relationship to subjective well-being in a developing region
}

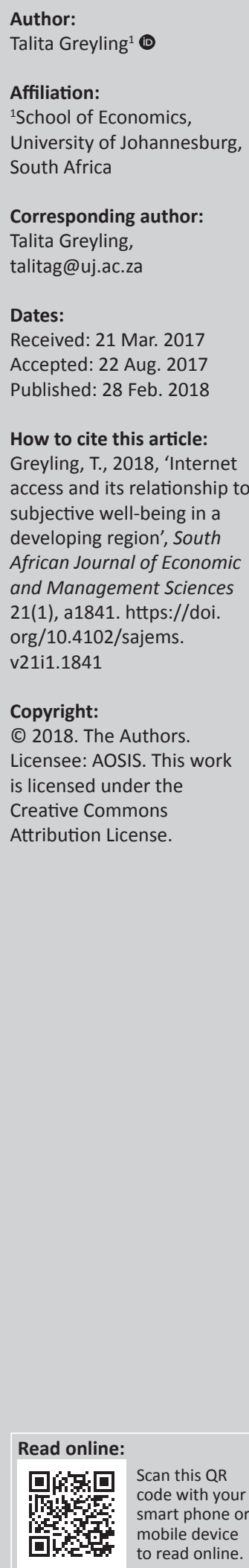

\begin{abstract}
Internet access has been shown to play an important developmental role and Internet access to all people has become an international goal. This is also true for South Africa where the 'South Africa Connect' policy was introduced in 2013. The question arises whether Internet access goes beyond meeting developmental goals to improving the subjective well-being of people. Furthermore, if the association between Internet access and subjective well-being vary between different race and age groups. Previous research was performed in developed countries at a national level or for specific small subsamples, like the elderly; however, this study contributes to the literature by analysing a substantial sample, at sub-national level, in a heterogeneous, unequal society, in a developing country. The benefit is that heterogeneities masked in studies at a national, macro level are highlighted in a study at a sub-national, micro level. This article investigated the relationship between subjective well-being and Internet access within a developing region with a heterogeneous, unequal society. The article used a data set representative of the Gauteng population, the economic centre of South Africa, which was collected in 2013 by the Gauteng City Region Observatory. To analyse the data, ordered probit, ordinary least square and instrumental variable regression techniques were used. The results show that Internet access is positively related to subjective well-being and this relationship holds across all race groups and all age groups, from 18 years to over 65 years of age. In addition, it seems that the stark inequalities between race groups present in South Africa are fading among younger generations. Based on the results, the 'South Africa Connect' policy, which aims to give Internet access to all people, including those in Gauteng, the region analysed, is supported, as it not only contributes to the development of the region but also to the life satisfaction of the citizens.
\end{abstract}

\section{Introduction}

This article examines the association between modern information and telecommunication technologies (ICTs), in particular the Internet and subjective well-being. Subjective well-being ${ }^{1}$ can be defined as a person's cognitive and affective evaluations of his or her life (Diener \& Ryan 2009) and is typically measured by a subjective measure of global life satisfaction or happiness (Andrew \& Withey 1976).

In recent years, ICT has been shown to be an important and positive contributing factor to the development of a country (United Nations 2001b; World Bank 2016). The Human Development Report of 2001 (United Nations 2001b) and the recently published World Development Report 2016 on Digital Dividends (World Bank 2016) note that technological advances enhance human capabilities such as a healthy life, knowledge, creativity and participation in the social, economic and political life of a community and impact on economic growth through productivity gains.

Based on the knowledge that ICT, and specifically Internet access, enhances development, many high-profile initiatives have been undertaken to increase awareness of the benefits of ICT investment and to promote policy measures for the deployment of telecommunications infrastructure- and the diffusion of ICT. Notable examples of these projects include the Digital Opportunities Task Force (DOT Force) (G-8 2000) of the Eight Industrialised Countries (G-8), the World Economic Forum (WEF) Global Digital Divide Initiative (GDDI) (2002) and the World Information Technology Forum (WITFOR) established by the International Federation of Information Processing (2003), the establishment of the United Nations ICT Task Force (2001a), which to developing countries has a broader legitimisation than other initiatives.

In South Africa, the contribution of Internet connectivity to development is also recognised, as is revealed by the Electronic Communications Act 2005 (Act No. 36 of 2005), through the implementation 1.In this article, the term 'subjective well-being', "life satisfaction' and quality of life are used interchangeably. 
of South Africa's broadband policy, known as 'South Africa Connect' (Republic of South Africa: Department of Communications 2013). This policy gives expression to South Africa's vision in the National Development Plan (National Planning Commission 2012) of 'a seamless information infrastructure by 2030' (RSA 2011). 'South Africa Connect' aims to provide all South Africans access to broadband services that have a minimum speed of 10 Megabits per second by 2030 .

However, the question that arises, and is addressed in this article, is whether Internet access, although found to be positively associated with development, also positively contributes to a person's own evaluation of his or her wellbeing.

Research on the association between Internet access and subjective well-being has been carried out; nonetheless, some limitations in these studies are evident. Previous studies either considered small samples of specific individuals such as the elderly (Cotten et al. 2012) or adolescents (Gross, Juvonen \& Gable 2002), or did analyses at a national level (Pénard, Poussing \& Suire 2013), which masks the heterogeneities found at sub-national levels. Furthermore, previous research focused on developed countries such as Luxembourg (Pénard et al. 2013) and various other European countries (Kavetsos \& Koutroumpis 2011), with limited research in developing countries. These limitations of previous research are addressed in this research paper by analysing a substantial sample of individuals at a subnational level in a developing country across different race and age groups.

The sub-national region in question is the Gauteng province, the economic centre of South Africa. It is one of the nine provinces of the country and hosts $22 \%$ of the population of 53 million people (Statistics South Africa 2015b). It is well suited for a study of this kind because of its diverse and heterogeneous population. Segregated development of race groups, prior to the establishment of a democracy in 1994, led to a very unequal distribution of income ${ }^{2}$ (Van der Berg 2011), with the biggest proportion of black people and mixed race people in the lower income groups and white people, Indian people or Asian people in the higher income groups. The age distribution in the region is also skew with a disproportional number of youths under the age of 25 , which creates its own challenges, such as a high youth unemployment rate $^{3}$ of $40 \%$ (Statistics South Africa 2015a).

To address the research questions, I analyse a cross-sectional survey data set collected in 2013 by the Gauteng City Region Observatory (GCRO) (2013), making use of probit-, ordinary least square (OLS) and instrumental variable regression (IVR) techniques.

2.The Gini-coefficient, which is an indication of the unequal distribution of income, is extremely high, at 0.7 for the province, and 0.63 for the country as a whole (IHS Regional Economic Explorer 2014).

3.The strict definition of unemployment considers a person to be unemployed only if they have taken active steps to look for work or to start some form of selfemployment in the 4 weeks prior to the interview.
The results of the study show that a positive and statistically significant relationship exists between the Internet variables and subjective well-being. Similar results are found in the analyses within different race and age groups. The only exception is for the Internet home variable, which was not statistically significant for respondents over 65 .

The rest of the article is structured as follows: The 'Theoretical approach and literature review' section shortly gives the theoretical underpinnings of the subjective well-being literature and reviews the literature pertinent to the current study. The 'Methodology' section sets out the methodology. The 'Data and the selection of the variables' section describes the data and the selection of the variables. The 'Results' section reports the results and the last section concludes the article.

\section{Theoretical approach and literature review}

\section{Theoretical approach}

According to Diener et al. (1999), there are two main theoretical approaches to explain the differences in individuals' subjective well-being. The first approach pertains to external (bottom-up) factors and is related to what Wilson (1967) describes as 'the fulfilment of needs' theory. The second approach refers to personal or internal (topdown) processes within individuals where, for example, personality explains differences in perceived subjective wellbeing (Diener et al. 1999).

The majority of the empirical research pertains to the first theoretical approach. The results in these studies show that desirable events increase subjective well-being, whereas undesirable events decrease subjective well-being (Stallings et al. 1997). It is this theoretical approach adopted in this article.

From the abovementioned, it can be deduced that if the Internet experience is a desirable event, it should increase subjective well-being, but if it is undesirable, a decrease in subjective well-being is expected. Theoretically, there are a few plausible reasons to describe Internet use as a desirable event, for example, its use to communicate with friends and family (Facebook) or for leisure (to watch movies) (Franzen 2003). It might be described as an undesirable event if its use leads to addiction or isolation (Li \& Chung 2006).

\section{Subjective well-being (life satisfaction)}

In recent years, there has been a proliferation of studies on subjective well-being focusing on the measurement and determinants of the concept (for a summary of the findings in the subjective well-being literature, see Diener et al. (1999) and Graham (2009) among others).

On the measurement of subjective well-being, the studies conclude that subjective assessments of well-being are meaningful and valid indicators of welfare and that they 
provide a more holistic picture than traditional objective indicators, such as income or consumption (Diener \& Seligman 2004; Frey \& Stutzer 2010). To measure subjective well-being, a question, such as 'how satisfied are you with your life as a whole?', is asked, of which the response categories vary between very satisfied and very dissatisfied (Andrew \& Withey 1976; Diener \& Suh 1997). In this study, this type of question is used to assess the subjective wellbeing of the respondents.

Regarding the determinants of subjective well-being, the results of the studies reveal a number of standard variables found to explain life satisfaction and which are seldom omitted in estimation functions. These determinants hold across countries and across time. The variables include health (Diener \& Seligman 2004), income (relative income) (Easterlin 1974), marriage (Diener et al. 1999), gender (Verme 2009), age (Blanchflower \& Oswald 2008), employment (Verme 2009), education (Witter et al. 1994) and race (Fontaine \& Yamada 2014). In general, the results show that being healthy, having a partner or being married (Clark \& Oswald 2002), being female, not being in your middle ages, between 35 and 50 years, having higher levels of education and being white, in the South African context (Posel \& Casale 2011), lead to higher levels of life satisfaction (Diener et al. 1999). Some studies have also shown that being widowed or divorced is negatively associated with subjective well-being (Graham 2009).

Other variables that also frequently appear to be statistically significant in explaining subjective well-being are the number of children in a household (there is no consensus on the relationship to life satisfaction), time spent with family and friends (positive), political ideology (higher levels of democracy increase life satisfaction), freedom of choice (positive), societal trust (positive) and religion (positive) (Helliwell 2003; Verme 2009). In this study, the standard variables found to explain subjective well-being are used as control variables to estimate the subjective well-being of the surveyed population.

\section{Internet access and subjective well-being}

The literature on Internet access and subjective well-being can broadly be divided into three groups: (1) literature that investigates the direct relationship between Internet access and subjective well-being, (2) literature that investigates the indirect relationship via social media and (3) literature that looks at the relationship between the purpose and duration of use of the Internet and subjective well-being. In this study, I only review the most relevant literature that pertains to group 1. (For readings on the other groups of literature, see Mitchell et al. (2011), Muusses et al. (2014), Nie et al. (2017), Sabatini and Sarracino (2014) and Wickramasinghe and Ahmad (2013), among others.)

By far the majority of the studies that investigated the direct relationship between Internet access and subjective wellbeing found a positive association; nevertheless, the reader is reminded that these studies were mostly undertaken in developed countries and the question if this relationship holds in heterogeneous regions in developing countries is still unanswered.

In the study of Kavetsos and Koutroumpis (2011) using pooled cross-sectional data for European countries, it was concluded that having a fixed or mobile phone, music players, personal computers and Internet access at home is associated with higher levels of subjective well-being. The study of Pénard et al. provides similar conclusions using Luxemburgish data extracted from the European Value Survey. The study finds that non-users are less satisfied with their lives than Internet users. Moreover, their results show that the positive influence of Internet use is stronger for younger users or those not satisfied with their income. Cotten et al. (2012) furthermore reveal that Internet access not only improves subjective well-being, but also reduces depression among older retired Americans over the age of 50 years.

A recent study by Ganju, Pavlou and Banker (2016) reaffirmed the pre-mentioned results. They investigated the role of ICT (number of fixed telephones, Internet and mobile phones) on the subjective well-being of countries. To measure the country-level subjective well-being, they used the Gallup World Poll data and for ICT data, they used the World Bank database. The study argues that ICT can improve the subjective well-being of people by developing their social capital, by achieving social equality, enabling access to health-related information and health services, providing education to disadvantaged communities and by facilitating commerce. Their results reveal that the level of ICT use in a country is statistically significant and positively related to subjective well-being. Furthermore, they find that less developed countries increase their levels of well-being with primarily mobile phones, while more developed countries increase their levels of well-being with any of the ICT systems.

Building on the subject of Internet use and subjective wellbeing, Pierewan and Tampubolon analyse the relationship before, during and after the financial crisis in Europe. They use the four waves of the European Survey, from 2004 to 2010 , in their analysis and a multi-level model to understand how contextual factors explain individual well-being. They find that before the financial crisis, Internet use was not associated with subjective well-being, but during 2007 and thereafter a positive relationship was found.

In the only study found to include countries from subSahara Africa, Graham and Nikolova (2013) report, using data from the Gallup World Poll, that subjective well-being is higher in countries with higher levels of access to the Internet and mobile banking than in countries with limited access; however, in these countries, increased levels of anger and frustration are also reported (Graham \& Nikolova 2013). 


\section{Methodology}

The generic model estimated in this research article is as follows:

$Y_{i}=\beta_{0}+\beta_{l}$ internet $_{i}+\lambda_{I} X_{i}+\dot{\varepsilon}_{i}$,

[Eqn 1]

where $Y_{i}$ represents the life satisfaction of individual $i$, internet refers to Internet access of the same individual (i), $X_{i}$ is a vector of demographic and economic variables and $\dot{\varepsilon}_{i}$ is the error term capturing all variances in the dependent variable not explained by the model.

As life satisfaction, the dependent variable specified in the model is ordinal of nature, the appropriate estimation technique is either an ordered probit or an ordered logit model (Wooldridge 2010). As the method, ordered probit, is favoured in the subjective well-being literature (see, among others, Bartram 2013; MacKerron 2012; Posel \& Casale 2011), this is the method of choice in the current study, although all models are also estimated using OLS. The choice of OLS is based on the findings of Ferrer-i-Carbonell and Frijters. Their findings show that the estimated coefficients, using ordered probit and OLS, are often similar in signs and levels of statistical significance, with the difference that OLS-estimated coefficients are directly interpretable in contrast to ordered probit's estimated coefficients $^{4}$ (Ferrer-i-Carbonell \& Frijters 2004).

Furthermore, as endogeneity is often an issue in the estimation of human behaviour, I also estimate the specified functions using IVRs. To find an adequate instrument for Internet access, thus a variable that is exogenous, which is uncorrelated with the error term and sufficiently strongly correlated with the endogenous variable, was a challenge and the options of variables to instrument Internet access were limited. I considered the possibilities and found 'having a laptop' the preferred choice, as it is strongly correlated to the Internet access variables $\left(r_{s}>0.5\right)$ and not highly correlated to the 'life satisfaction' variable $\left(r_{s}=0.15\right)$. I ran diagnostics on all estimated regressions.

\section{Data and the selection of the variables \\ Data}

A cross-sectional survey data set, collected by the GCRO in 2013 (GCRO 2013) and made available in 2014, is used in all analyses. It includes, among others, objective and subjective measures of the different dimensions of quality of life and questions referring to Internet access, which makes it ideal for the current research.

The sample is representative of the Gauteng population aged 18 years and older and includes 27490 respondents in the 10 municipalities of Gauteng (Geospace International prepared for the GCRO 2014).

4.Probit estimated coefficients predict the probability (derived from the computed odd ratios) that the dependent variable is in a specific category. Though often the interpretation of probit coefficients is not as accurate as using OLS estimations.
In the current study, the secondary research question relates to analyses per race and age groups: Four different race groups are defined in the data set including black people, white people, mixed race people and Asian people or Indian people (Table 2). To divide the sample according to age groups, I recoded the age variable into four categories: under 20 , younger adults from 20 to 39 , which are by far the biggest group, older adults from 40 to 64 and respondents of pensionable age from 65 and older (Table 1).

\section{Selection of variables}

\section{Life satisfaction}

To measure subjective well-being, I followed the standard practice (see Andrew \& Withey 1976) and used the survey question related to life satisfaction. The question is: 'How satisfied are you with your life as a whole these days?' The respondents have five options to choose from, ranging from very satisfied to very dissatisfied.

Figure 1 shows the distribution of the life satisfaction variable, with the majority of the sample (69\%), indicating that they are satisfied or very satisfied and only $21 \%$ of the sample showing that they are dissatisfied or very dissatisfied with life.

Decomposing and comparing the life satisfaction variable for the different race groups, I find the percentage of white people reporting to be satisfied with life (89\%), much higher than that reported by black people $(66 \%)$ or mixed race people $(76 \%)$.

Comparing life satisfaction among the four age categories (Figure 2), the standard U-shaped relationship between life satisfaction

TABLE 1: Race and age groups in Gauteng.

\begin{tabular}{lc}
\hline Variable & Sample (\%) \\
\hline Race & \\
Black people & 83.9 \\
White people & 10.6 \\
Mixed race people & 3.3 \\
Asian people or Indian peoplet & 1.8 \\
Age & \\
Under 19 & 4 \\
20-39 & 52 \\
$40-64$ & 36 \\
$65+$ & 8 \\
\hline
\end{tabular}

$\dagger$, Asian people or Indian people were too few for robust statistical analysis and thus were excluded from further analyses.

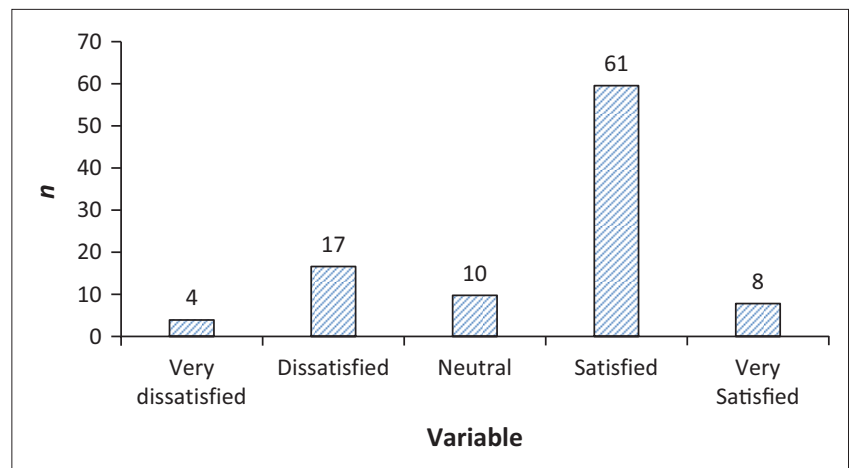

FIGURE 1: Life satisfaction (frequency \%). 
and age, found in the literature, is observed (Blanchflower \& Oswald 2008). However, in this data set, it seems as if the lowest levels of life satisfaction are experienced within an earlier age category of between 20 and 39 years compared to 35-50 years reported by Blanchflower and Oswald (2008).

\section{Regressors}

The selection of the regressors was based on the standard variables found in the literature to explain subjective wellbeing ('Subjective well-being' section), but also including

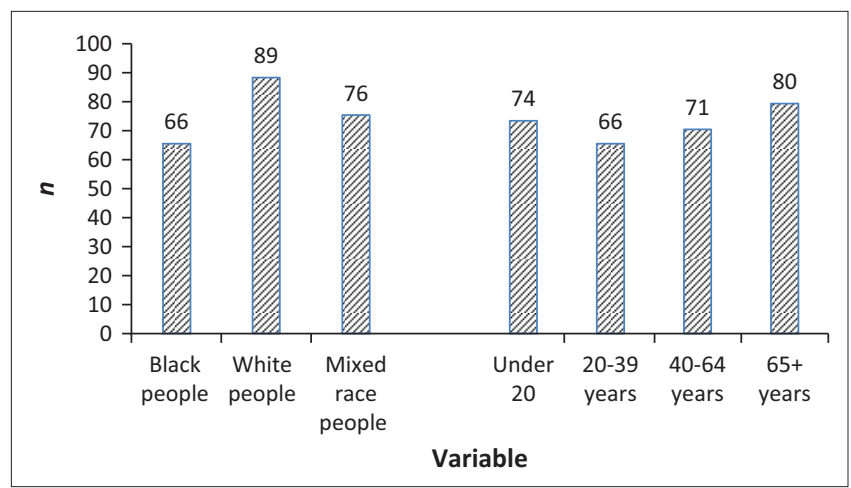

FIGURE 2: Life satisfaction per race and age groups (frequency \%). the Internet access variables, which are the variables of interest.

Variables of interest - Internet accessed and Internet home: The survey included two questions related to the Internet. The first question determines if the respondent has Internet at home (Internet home) and the second question enquires whether the respondent accessed the Internet at any location during the 4 weeks prior to the interview (Internet accessed). It is likely that the two Internet variables might reflect different time spans with the Internet at home variable possibly indicating a longer period of access than the variable measuring if a respondent accessed the Internet in the past 4 weeks. To accommodate these time span differences, I estimate two separate functions including the different Internet variables, respectively. If the results of the regressions are similar, it reflects the robustness of the findings. I report the results of the Internet accessed variable in the body of the article and the results on the Internet home variable in Appendix 1.

Table 2 shows that $17 \%$ of the respondents had Internet access at home and a far bigger proportion of $33 \%$ had access to the Internet 4 weeks prior to the interview (GCRO 2013). Of those respondents who accessed the Internet, they got

TABLE 2: Regressors.

\begin{tabular}{|c|c|c|c|c|}
\hline Variable & Description & Coding & Mean or frequency ( $\%$ of sample) & Standard deviation \\
\hline Internet accessed & Accessed Internet in the past 4 weeks & 1 = affirmative & 0.34 & 0.48 \\
\hline Internet home & Has Internet at home & $1=$ affirmative & 0.17 & \\
\hline Gender & Male or female & $1=$ male & 0.51 & 0.96 \\
\hline Marital status & Married or with a partner & $1=$ married & 0.79 & 0.41 \\
\hline Employment & Did any type of work in the past 7 days? & 1 = employed & 0.43 & 0.49 \\
\hline Health & Respondent does not usually need health care & 1 = healthy & 0.04 & 0.19 \\
\hline Black people & Reference group & Not coded & 0.84 & - \\
\hline Race: mixed race people & Mixed race people & $1=$ mixed race person & 0.03 & - \\
\hline Race: white people & White people & $1=$ white person & 0.11 & - \\
\hline \multirow[t]{6}{*}{ Education } & Highest level of education completed (ordered variable) & & & - \\
\hline & No Education & 1 & $2.1 \%$ & - \\
\hline & Primary education (grades $0-7$ ) & $2-9$ & $12.5 \%$ & - \\
\hline & Secondary education - incomplete (grades 8-11) & $10-13$ & $35.8 \%$ & - \\
\hline & Grade 12 & 14 & $29.1 \%$ & - \\
\hline & More & $15-18$ & $19.3 \%$ & - \\
\hline \multirow[t]{6}{*}{ Satisfaction with money } & Satisfaction: money available to respondent personally & & & \\
\hline & Very dissatisfied & 1 & $17.7 \%$ & - \\
\hline & Dissatisfied & 2 & $47.2 \%$ & - \\
\hline & Neutral & 3 & $6.9 \%$ & - \\
\hline & Satisfied & 4 & $25.6 \%$ & - \\
\hline & Very satisfied & 5 & $2.6 \%$ & - \\
\hline \multirow[t]{9}{*}{ Income } & Individual income per month & & & \\
\hline & RO & 0 & $6.6 \%$ & - \\
\hline & R1- R640 & 1 & $7.7 \%$ & - \\
\hline & R641-R1280 & 2 & $42.9 \%$ & - \\
\hline & R1281-R5120 & 3 & $36.6 \%$ & - \\
\hline & R5121-R10 240 & 4 & $3.7 \%$ & - \\
\hline & R10 240-R20 480 & 5 & $1.5 \%$ & - \\
\hline & R20 481-R40 960 & 6 & $1.4 \%$ & - \\
\hline & R40.961+ & 7 & $1.1 \%$ & - \\
\hline Age & Age of respondent & - & 40 & 15.54 \\
\hline Age $^{2}$ & Age of respondent ${ }^{2}$ & - & 1814.53 & 1412.77 \\
\hline Social relationships & Composite index of social relationships & - & 3.90 & 0.723 \\
\hline Religion & Attend religious gathering & $1=$ religious & 0.43 & 0.49 \\
\hline
\end{tabular}


access in the following ways: via mobile phones (45.6\%), from home $(24.4 \%)$, from work $(16.8 \%)$, from Internet cafes $(7 \%)$, from schools, colleges or universities $(4 \%)$ and from community centres or libraries (2\%).

The majority of the respondents that accessed the Internet had an education level of matric or more $(80.9 \%)$, were between the ages of 20 and $39(61.3 \%)$, were male (55.2\%) and were black people (61.3\%) (GCRO 2013). Based on the aforementioned, the majority of the current Internet users in Gauteng can be described as young, educated, black people respondents, with little to choose among the genders. It should also be noted that, within the race groups, the majority of Asian people (59.4\%) and white people (64.9\%) accessed the Internet, compared to only $28.7 \%$ of the black people (GCRO 2013).

Other repressors - The standard variables found to explain life satisfaction: Based on the literature reviewed in the 'Subjective well-being' section, the following standard variables were included in the life satisfaction model: gender, race, age, age $^{2}$, being married or living with a partner, education, health, employment status, income and satisfaction with money.

Table 2 gives each variable's name, an explanation of the variable, a description of the coding and descriptive statistics. In addition, I give information on the selection of the method used to generate- and the recoding of variables.

The health variable was derived from a question that asked if a person usually needs health care, assuming that if a person needs health care he or she is not healthy and vice versa.

Education is a discrete variable that was recoded to take a value of 1 if the respondent has no education, 2 if the respondent has Grade 0, 3 if the respondent has Grade 1, 4 if the respondent has Grade 2, and so forth, up to a maximum of 18 representing a respondent that has a post graduate degree (in Table 2 frequencies for specific grade groups are indicated).

The survey included two variables related to income. The first measured the income of a household per month and the other determined the satisfaction of a respondent with the money available to him or her personally, which is a subjective measure of income; both of these measures were included in the estimated model.

The household income variable was categorical and reported total household income, including income from employment, government grants and remittances. I transformed the variable to reflect individual income by making use of the average number of adults per household (2.5) (Table 2). A substantial proportion (27\%) of the respondents chose not to answer the income question, which made analysis based on the income variable problematic, especially seeing that the missingness was most likely not random. To address the missingness in the data, I imputed the income variable using the mode of nearby points, as this method is most likely to capture the approximate distribution of the income variable.
The reported income per household varied between 'no income' and more than R500 $000(\$ 34722)^{5}$ per month, which indicates the inequality in income levels in the province.

To measure social relationship, I compiled a composite index, derived from the first extracted principal component, ${ }^{6}$ which included the variables 'satisfaction with time available for friends', 'for family' and the number of community meetings attended during the year.

The religion variable was derived from the question if a person attended a church or religious organisation in the past.

The expected relationship between the repressors and subjective well-being is as follows: concerning gender, females generally report higher levels of life satisfaction than males (Alesina, Di Tella \& MacCulloch 2004), but the opposite has also been found (Andrew \& Withey 1976). Being married or living with a partner has been shown to be positively related to life satisfaction (Diener et al. 1999; Helliwell 2003). Being unemployed has largely been found to be negatively correlated to subjective well-being (Helliwell 2003).

Contrary to the general findings in the literature (Diener \& Seligman 2004; Helliwell 2003), studies in South Africa have shown that the relationship between health and subjective well-being is statistically not significant (Blaauw \& Pretorius 2013). Furthermore, race has been shown to be statistically significant in explaining life satisfaction (Fontaine \& Yamada 2014) and in South African literature, it has been shown that black people are often less satisfied with their lives than other race groups (Greyling \& Tregenna 2016).

The relationship between education and subjective wellbeing is not clear and often not statistically significant in explaining subjective well-being when controlling for health and income (Blanchflower \& Oswald 2004). Nevertheless, some studies do find a positive relationship (Witter et al. 1994).

Literature mostly reveals a positive relationship, up to a certain point (Easterlin 1974), between income and subjective well-being, the same holds for the satisfaction with money variable. It is interesting, however, to note that almost $65 \%$ of the sample indicated that they were not satisfied with the amount of money available to them, reflecting a sense of relative poverty in the region.

Previous literature has shown that there is a U-shaped relationship between age and life satisfaction (Blanchflower \& Oswald 2008). Based on these findings, I included an age variable and an age $^{2}$ variable to control for the non-linear effects of age. Social relationships have been shown to be positively related to life satisfaction (Helliwell 2003) and 5.SA Rand, US dollar exchange rate on 25 July 2016: $\$ 1=$ R14.40. 6.See the Handbook on the Constructing of Composite Indicators (OECD 2008) for a more detailed description on the construction of Composite indices using Principal Components Analysis (PCA) 
TABLE 3: Estimation results for subjective well-being (whole sample).

\begin{tabular}{|c|c|c|c|c|c|c|}
\hline \multirow[t]{2}{*}{ Regressor } & \multicolumn{2}{|c|}{ Ordered probit } & \multicolumn{2}{|c|}{ OLS } & \multicolumn{2}{|c|}{ IV } \\
\hline & Coefficient & Standard error & Coefficient & Standard error & Coefficient & Standard error \\
\hline Gender & $-0.049 * *$ & 0.015 & $-0.037 * *$ & 0.012 & $-0.048 * * *$ & 0.012 \\
\hline Marital status & 0.032 & 0.018 & $0.032 *$ & 0.014 & $0.030 *$ & 0.014 \\
\hline Employment & $0.077 * * *$ & 0.016 & $0.070 * * *$ & 0.012 & $0.050 * * *$ & 0.013 \\
\hline Health & 0.025 & 0.038 & 0.0261 & 0.030 & 0.036 & 0.030 \\
\hline Race: mixed race people & 0.051 & 0.030 & 0.041 & 0.025 & 0.003 & 0.025 \\
\hline Race: white people & $0.189 * * *$ & 0.025 & $0.119 * * *$ & 0.017 & $0.048 *$ & 0.023 \\
\hline Education level & $0.012 * * *$ & 0.003 & $0.008 * * *$ & 0.002 & $0.002 *$ & 0.003 \\
\hline Satisfaction with money & $0.271 * * *$ & 0.007 & $0.211 * * *$ & 0.005 & $0.204 * * *$ & 0.005 \\
\hline Income & $0.013 * * *$ & 0.001 & $0.011 * * *$ & 0.001 & $0.009 * * *$ & 0.001 \\
\hline Age & $-0.008 * *$ & 0.003 & $-0.005 * *$ & 0.002 & $-0.005 * *$ & 0.002 \\
\hline $\mathrm{Age}^{2}$ & $0.0002 * * *$ & 0.000 & $0.0002 * * *$ & 0.000 & $0.0002 * *$ & 0.000 \\
\hline Social relationships & $0.292 * * *$ & 0.012 & $0.226 * * *$ & 0.009 & $0.221 * * *$ & 0.008 \\
\hline Religion & $-0.045 * *$ & 0.015 & $-0.025 *$ & 0.012 & $-0.041 * * *$ & 0.012 \\
\hline Constant & - & - & $1.873 * * *$ & 0.058 & $1.873 * * *$ & 0.058 \\
\hline Cut1 constant & 0.0824 & 0.074 & - & - & - & - \\
\hline Cut2 constant & $1.185 * * *$ & 0.074 & - & - & - & - \\
\hline Cut3 constant & $1.532 * * *$ & 0.074 & - & - & - & - \\
\hline Cut4 constant & $3.690 * * *$ & 0.077 & - & - & - & - \\
\hline$N$ & 25447 & - & 25447 & - & 25447 & - \\
\hline Adjustedor psuedo- $R^{2}$ & 0.069 & - & 0.142 & - & 0.142 & - \\
\hline Significance & 0.000 & - & 0.000 & - & 0.000 & - \\
\hline
\end{tabular}

OLS, making use of probit- ordinary least square; IV, instrumental variable regression

Note: All models are estimated using robust standard errors to address heteroscedasticity. 'Laptop' is used to instrument Internet accessed.

$*, p<0.05 ; * *, p<0.01 ; * * *, p<0.001$.

studies on religion fairly consistently suggest that regular engagement in religious activities is positively related to subjective well-being (Clark \& Lelkes 2005).

\section{Results}

\section{Results for the sample as a whole}

All estimations were executed using the two Internet variables, respectively. However, in this section, I only report the results on the Internet accessed variable, whereas the results on the Internet home variable are reported in Appendix 1. I found the results on the two Internet variables very similar and identical in signs and level of statistical significance; therefore, I deem the findings related to the Internet variables robust.

As was explained in the 'Methodology' section, I used ordered probit, OLS and IVR techniques to estimate the subjective well-being function. Table 3 shows that the signs and levels of statistical significance of the three estimation techniques are in general similar, although the size of the estimated coefficients differs. Therefore, according to Ferreri-Carbonell and Frijters (2004), the OLS- or IVR-estimated coefficients are preferred, depending on the presence of endogeneity.

Testing the hypothesis that Internet accessed is exogenous, the Wooldridge's (2010) robust score test $\left(c h i^{2}=42.410\right)$ and the robust regression-based test $(F=42.722)$ were statistically significant $(p=0.000)$, and therefore the null hypothesis was rejected, accepting the alternative that Internet accessed is endogenous. To test the strength of the instrument, I used the
Cragg-Donald Wald $F$-statistic $(F=2816.289)$ that was greater than the Stock Yogo's weak ID critical value at $10 \%{ }^{7}$ of 16.38 . Therefore, it was concluded that the instrument was strong. Accepting the endogenous nature of the Internet variables, I interpret the IVR estimations.

I found the IVR-estimated model statistically significant with $F=304.02(p=0.000)$; furthermore, the model explained $14 \%$ (Adjusted $R^{2}$ ) of the variance in life satisfaction, which is relatively low but acceptable in the subjective well-being literature.

Looking at the regressors, I find Internet accessed to be statistically significant and positively related to life satisfaction; this was also true if I considered the relationship between Internet home (Appendix 1) and life satisfaction. These findings indicate that Internet access, irrespective of the time period under consideration, is positively related to life satisfaction. The results are in line with the findings of previous literature; see Kavetsos and Koutroumpis (2011), Cotten et al. (2012) and Ganju et al. (2016), among others. Furthermore, as Internet access is endogenous, simultaneity might be plausible, suggesting that people who are more satisfied with their lives are more likely to access the Internet than those less satisfied.

This finding at micro level, confirming a positive relationship between life satisfaction and Internet access, is in line with the macro level perspectives, which indicates that Internet access is positively related to development. Accordingly, Internet access is not only beneficial to the development of a 7.Accepted level of size distortion. 
TABLE 4: Instrumental variable regression estimation results for subjective well-being (race groups).

\begin{tabular}{|c|c|c|c|c|c|c|}
\hline \multirow[t]{2}{*}{ Regressors } & \multicolumn{2}{|c|}{ Black people } & \multicolumn{2}{|c|}{ White people } & \multicolumn{2}{|c|}{ Mixed race people } \\
\hline & Coefficient & Standard error & Coefficient & Standard error & Coefficient & Standard error \\
\hline Gender & $-0.041 * *$ & 0.014 & -0.031 & 0.025 & -0.096 & 0.059 \\
\hline Marital status & 0.019 & 0.016 & $0.072 *$ & 0.035 & $0.227 * * *$ & 0.068 \\
\hline Employment & $0.072 * * *$ & 0.014 & 0.012 & 0.028 & -0.018 & 0.066 \\
\hline Health & 0.010 & 0.033 & 0.216 & 0.113 & 0.254 & 0.204 \\
\hline Education level & $0.007 * *$ & 0.002 & 0.01 & 0.007 & 0.018 & 0.014 \\
\hline Satisfaction with money & $0.219 * * *$ & 0.006 & $0.096 * * *$ & 0.011 & $0.205 * * *$ & 0.026 \\
\hline Income & $0.011 * * *$ & 0.001 & 0.001 & 0.003 & 0.005 & 0.005 \\
\hline Age & $-0.007 * *$ & 0.002 & $-0.010 *$ & 0.004 & $-0.020 *$ & 0.010 \\
\hline $\mathrm{Age}^{2}$ & $0.001 * * *$ & 0.000 & $0.001 * *$ & 0.000 & $0.001 *$ & 0.000 \\
\hline Social relationships & $0.223 * * *$ & 0.009 & $0.244 * * *$ & 0.019 & $0.268 * * *$ & 0.044 \\
\hline Religion & $-0.032 *$ & 0.013 & 0.007 & 0.025 & $-0.137^{*}$ & 0.059 \\
\hline Internet accessed & $0.299 * * *$ & 0.043 & $0.124 *$ & 0.056 & $0.336 *$ & 0.159 \\
\hline Constant & $1.914 * * *$ & 0.066 & $2.568 * *$ & 0.152 & $1.886 * * *$ & 0.299 \\
\hline Adjusted $R^{2}$ & 0.115 & - & 0.094 & - & 0.146 & - \\
\hline Probability & 0.000 & - & 0.000 & - & 0.000 & - \\
\hline
\end{tabular}

Note: All models are estimated using robust standard errors to address heteroscedasticity. 'Laptop' is used to instrument Internet accessed.

$*, p<0.05 ; * *, p<0.01 ; * * *, p<0.001$

country as a whole, but also to the life satisfaction of individuals. Furthermore, based on the theoretical assumptions of the bottom-up approach, it seems as if Internet uses for desirable events outweigh the use for undesirable events. Implying that Internet use is put to worthy and desirable activities in Gauteng such as job searches, gives access to online banking and shopping, information (Ganju et al. 2016) and increased social interaction via social media (Sey et al. 2013).

Considering the other regressors, all the standard variables found in the literature to be associated with life satisfaction were also statistically significant in this model, with the exception of health. Furthermore, the religion variable's sign is negative contravening previous findings.

The result on the health variable is unexpected, as previous literature has shown that health is positively related to life satisfaction (Diener \& Seligman 2004). The health variable is derived from a response that indicates that a person does not usually need health care and therefore is assumed to be healthy, as the question does not directly assess the health status of a person; it is likely that the question underestimates the importance of health in explaining life satisfaction.

Religion is statistically significant though it has the opposite sign to what was expected, indicating that being religious is negatively related to life satisfaction. This finding differs from the study of Greyling (2015) on forced migrants in Gauteng where she found no statistical significance and the study of Blaauw and Pretorius (2013) who found a positive relationship. From these contradicting results, it seems that the relationship between religion and life satisfaction in a South African scenario is still contested.

Furthermore, pertaining to race, the mixed race variable is not statistically significant, showing that being mixed race compared to being a black person does not warrant higher levels of life satisfaction in Gauteng. However, being a white person is statistically significant showing that a white person relative to other race groups is likely to enjoy higher levels of life satisfaction. This result reflects the inequalities between race groups in Gauteng, which is likely the remains of the previous political dispensation, in which white people received certain rights and socio-economic privileges denied to other race groups. The political dispensation ended with the democratisation of South Africa in 1994.

\section{Results per race group}

The results in this section are reported per race group; therefore, the variables related to race used in the previous estimations are omitted from these models.

All the models, as in the previous section, were estimated using ordered probit, OLS and IVR estimation techniques. After conducting post-estimation tests, I found that the endogenous nature of the Internet variables ${ }^{8}$ was also present when estimating the subjective well-being function per race group; thus, I only report and interpret the IVR estimation results (Table 4). The estimated models per race group were all statistically significant and explained between $11 \%$ and $15 \%\left(R^{2}\right)$ of the variance in the life satisfaction variable (Table 4 ).

All the estimated functions per individual race group found the Internet accessed variable (Table 4) statistically significant and positively related to life satisfaction. This indicates that access to the Internet contributes to all race groups' life satisfaction. Therefore, from a policy point of view, all people in Gauteng, irrespective of their race, should have access to the Internet, as Internet access can improve their well-being.

The gender variable, interestingly, is only statistically significant in explaining the life satisfaction in the model pertaining to black people respondents, implying that black

8.Because of space limitations, the models, including 'internet home' and all ordered probit and OLS estimation results, are not published but available on request from the author. 
TABLE 5: Instrumental variable regression estimation results for subjective well-being (age groups).

\begin{tabular}{|c|c|c|c|c|c|c|c|c|}
\hline \multirow[t]{2}{*}{ Variable } & \multicolumn{2}{|c|}{ Ages 0-19 } & \multicolumn{2}{|c|}{ Ages 20-39 } & \multicolumn{2}{|c|}{ Ages 40-64 } & \multicolumn{2}{|c|}{ Ages 65+ } \\
\hline & Coefficient & Standard error & Coefficient & Standard error & Coefficient & Standard error & Coefficient & Standard error \\
\hline Gender & -0.07 & 0.068 & $-0.055 * *$ & 0.018 & $-0.059 * *$ & 0.020 & $-0.059 * *$ & 0.020 \\
\hline Marital status & 0.046 & 0.062 & 0.043 & 0.023 & 0.013 & 0.024 & 0.013 & 0.024 \\
\hline Employment & $-0.362 * *$ & 0.129 & $0.086 * * *$ & 0.017 & 0.023 & 0.020 & 0.023 & 0.020 \\
\hline Health & 0.129 & 0.122 & 0.003 & 0.039 & 0.051 & 0.059 & 0.051 & 0.059 \\
\hline Race: mixed race people & -0.09 & 0.120 & 0.032 & 0.034 & -0.029 & 0.037 & -0.029 & 0.037 \\
\hline Race: white people & 0.083 & 0.096 & $0.110 * * *$ & 0.031 & $0.075^{*}$ & 0.033 & $0.075^{*}$ & 0.033 \\
\hline Education level & -0.024 & 0.034 & $-0.013^{*}$ & 0.006 & 0.005 & 0.004 & 0.006 & 0.004 \\
\hline Satisfaction with money & $0.229 * * *$ & 0.027 & $0.213 * * *$ & 0.008 & $0.201 * * *$ & 0.009 & $0.201 * * *$ & 0.009 \\
\hline Income & $0.012^{*}$ & 0.006 & $0.009 * * *$ & 0.002 & $0.010 * * *$ & 0.002 & $0.010 * * *$ & 0.002 \\
\hline Social relationships & $0.163 * * *$ & 0.048 & $0.207 * * *$ & 0.013 & $0.234 * * *$ & 0.016 & $0.234 * * *$ & 0.016 \\
\hline Religion & -0.117 & 0.070 & $-0.074 * * *$ & 0.018 & -0.002 & 0.019 & -0.002 & 0.019 \\
\hline Internet accessed & $0.767 * *$ & 0.293 & $0.401 * * *$ & 0.065 & $0.276 * * *$ & 0.066 & $0.276 * * *$ & 0.066 \\
\hline Constant & $2.154 * * *$ & 0.417 & $2.070 * * *$ & 0.090 & $2.008 * * *$ & 0.079 & $2.008 * * *$ & 0.079 \\
\hline Adjusted $R^{2}$ & 0.071 & - & 0.11 & - & 0.135 & - & 0.135 & - \\
\hline Probability & 0.000 & - & 0.000 & - & 0.000 & - & 0.000 & - \\
\hline
\end{tabular}

Note: All models are estimated using robust standard. 'Laptop' is used to instrument Internet accessed.

$*, p<0.05 ; * *, p<0.01 ; * * *, p<0.001$.

females are more satisfied with their lives than males. For the white- and mixed race people estimated models, the gender variable is not statically significant, therefore showing that gender within these race groups is irrelevant in explaining life satisfaction.

The socio-economic status variables (SES), namely, employment status, education and income, are statistically significant and positively related to the life satisfaction in the African estimated model, but not in the other estimated models. This is likely a reflection of the inequalities within the Gauteng province, which is along racial lines, with black people often having lower levels of education, higher levels of unemployment and lower levels of income than the other race groups (Statistics South Africa 2015). Any improvement in SES will positively contribute to the subjective well-being of black people. Where the SES variables in the white people' and mixed race' models are not statistically significant, maybe showing that to improve the latter race group's life satisfaction higher order needs, such as self-fulfilment, should be reached (Maslow 1943).

Interesting to note that the subjective measure, measuring the amount of money available to an individual, is statistically significant and positively related to the life satisfaction of all the race groups, indicating that subjective measures capture different sentiments than objective measures.

\section{Results per age group}

To estimate the life satisfaction function per age group, I grouped the sample into four age categories (Table 2). I omitted the age and age ${ }^{2}$ variables from the estimated models as each age categories' life satisfaction was estimated individually.

After using probit, OLS and IV regression techniques to estimate the life satisfaction models per age group, the postestimation tests showed that the Internet variables were endogenous as was found in the estimation of the sample as a whole and per race group. I therefore report and interpret the IVR estimation results (Table 5). All the models estimated per age categories were statistically significant and explained between $11 \%$ and $15 \%\left(R^{2}\right)$ of the variance in life satisfaction.

The Internet access variable is statistically significant and positively related to life satisfaction for each estimated model per age group (Table 5). This finding also holds for Internet at home, with the exception of those respondents who are 65 and older. ${ }^{9}$ Thus, the 'South Africa Connect' policy to provide Internet access to all people is likely to improve the subjective well-being of people across all age groups.

The results on the majority of the other control variables are in line with those found for the whole sample; however, the race white, employment status and education variables' results differ somewhat per age group (Table 5). The race white variable is not statistically significant for respondents under the age of 20, although it is statistically significant for older respondents. This might indicate higher levels of equality for younger age groups who are facing similar educational and employment challenges. Furthermore, one should keep in mind that this age group, in general, enjoys higher levels of life satisfaction than those in the age group between 20 and 39 years of age.

The employment variable is statistically significant and positive for the younger age groups up to the age of 39. From the age of 40 , the employment variable is no longer statistically significant. Often, the younger people struggle to find employment, whereas respondents who are older and have more experience are likely to be employed and therefore employment is not necessarily a predictor of their life satisfaction. Employment was also found not to be statistically significant for respondents aged 65 and older as they are of pensionable age and employment no longer plays a role.

9.Because of space constraints, these results are not published but are available on request. 


\section{Conclusion}

In this article, I investigated the relationship between subjective well-being and Internet access at a sub-national level in a developing country. The research article in particular also investigated the relationship across different race and age groups. The region analysed was the Gauteng province in South Africa, which is known for high levels of inequalities among race and age groups in terms of income, education, employment levels and access to infrastructure.

The article firstly contributes by analysing the relationship between subjective well-being and Internet access at a subnational level in a very diverse region. Secondly, it investigated this relationship in a developing country, which is particularly relevant as Internet access is seen as a development tool. Thirdly, it used a substantial sample representative of the region, in contrast to many of the previous studies that only looked at relatively small samples of specific individuals, such as adolescents (Gross et al. 2002) or the elderly (Cotten et al. 2012). To the author's knowledge, this is the first study of its kind.

To analyse the research questions, I made use of a data set collected in 2013 on the quality of life of the people in Gauteng (GCRO 2013). All estimations were performed using ordered probit, OLS and IVR estimation techniques. Post-estimations tests revealed that the Internet access variables were endogenous; therefore, I interpreted the IVR results.

The results showed that life satisfaction and the Internet access variables, namely, Internet accessed and Internet home, were positively related and statistically significant, implying that higher levels of access to the Internet improve the subjective well-being of all people notwithstanding their race or age. The results of a positive relationship agree with studies such as Kavetsos and Koutroumpis (2011), Cotten et al. (2012), Ganju et al. (2016) and Pierewan and Tampubolon (2014). Furthermore, these results support the 'South Africa Connect' policy implemented by the South African Government, which aims to give Internet access to all South Africans by 2030 as it not only contributes to the development of the region but also to the life satisfaction of the citizens.

When the models were estimated per race and age groups, the results confirmed the findings of the sample as a whole. Interesting for the age group under 20, being a white person did not imply higher levels of life satisfaction than being a black person. This suggests a more equal society for younger respondents.

As it is likely that Internet access to certain groups will be prioritised, it seems that younger age groups will benefit most as it gives them access to knowledge, education and employment possibilities (Pénard et al. 2013). Furthermore, judging from groups experiencing lower levels of life satisfaction compared to others, like black people, measures taken to give Internet access to these groups may improve their life satisfaction. In so doing, current inequalities within the Gauteng province can be addressed.
The current study has limitations, as the analysis is crosssectional. A future longitudinal study could reveal more insightful results. Furthermore, research on the specific use of Internet access and the time spent online could be valuable for policy development in the future.

\section{Acknowledgements}

I would like to thank the GCRO for giving me access to their data set on the quality of life in Gauteng.

\section{Competing interests}

The author declares that she has no financial or personal relationships that may have inappropriately influenced her in writing this article.

\section{References}

Alesina, A., Di Tella, R. \& MacCulloch, R., 2004, 'Inequality and happiness; are Europeans and Americans different?', Journal of Public Economics 88(9-10), 2009-2042. https://doi.org/10.1016/j.jpubeco.2003.07.006

Andrew, F.M. \& Withey, S.B., 1976, Social indicators of well-being: Americans perceptions of quality of life, Plenum Press, New York.

Blaauw, D. \& Pretorius, A., 2013, 'The determinants of subjective well-being in South Africa-an exploratory enquiry', Journal of Economic and Financial Science 6(1), 179-194.

Blanchflower, D.G. \& Oswald, A.J., 2004, 'Well-being over time in Britain and the USA', Journal of Public Economics 88(7), 1359-1386. https://doi.org/10.1016/S00472727(02)00168-8

Blanchflower, D.G. \& Oswald, A.J., 2008, 'Is well-being U-shaped over the life cycle?', Social Science \& Medicine 66(8), 1733-1749. https://doi.org/10.1016/j. socscimed.2008.01.030

Clark, A. \& Lelkes, O., 2005, Deliver us from evil: Religion as insurance, PSE Working Papers, n 2005-43, HAL Id: halshs-00590570, viewed n.d., from https://halshs. archives-ouvertes.fr/halshs-00590570

Clark, A.E. \& Oswald, A.J., 2002, 'A simple statistical method for measuring how life events affect happiness', International Journal of Epidemiology 31(6), 1139-1144. https://doi.org/10.1093/ije/31.6.1139

Cotten, S.R., Ford, G., Ford, S. \& Hale, T.M., 2012, 'Internet use and depression among older adults', Computers in Human Behavior 28(2), 496-499. https://doi.org/ 10.1016/j.chb.2011.10.021

Bartram, D., 2013, 'Migration, return, and happiness in Romania', European Societies $15(3), 408-422$.

Diener, E. \& Ryan, K., 2009, 'Subjective well-being: A general overview', South African Journal of Psychology 39(4), 391-406. https://doi.org/10.1177/0081246309 03900402

Diener, E. \& Seligman, M., 2004, 'Toward an economy of well-being', Psychological Science in the Public Interest 5(1), 1-31. https://doi.org/10.1111/j.09637214.2004.00501001.x

Diener, E. \& Suh, E., 1997, 'Measuring quality of life: Economics, social, and subjective indicators', Social Indicators Research 40(1-2), 189-216. https://doi.org/ 10.1023/A:1006859511756

Diener, E., Suh, E.M., Lucas, R.E. \& Smith, H.L., 1999, 'Subjective well-being: Three decades of progress', Psychological Bulletin 125(2), 276-302. https://doi.org/ 10.1037/0033-2909.125.2.276

Easterlin, R.A., 1974, 'Does economic growth improve the human lot?', in P.A. David \& M.W. Reder (eds.), Nations and households in economic growth: Essays in hono of Moses Abramovitz, pp. 89-125, Academic Press, Inc., New York.

Ferrer-i-Carbonell, A. \& Frijters, P., 2004, 'How important is methodology for the estimates of the determinants of Happiness?', Economic Journal, Royal Economic Society 114(497), 641-659.

Fontaine, X. \& Yamada, K., 2014, 'Caste comparisons in India: Evidence from subjective well-being data', World Development 64, 407-419. https://doi.org/10.1016/j. worlddev.2014.06.025

Franzen, A., 2003, 'Social capital and the Internet: Evidence from Swiss panel data' Kyklos 56(3), 341-360. https://doi.org/10.1046/j.0023-5962.2003.00224.x

Frey, B.S. \& Stutzer, A., 2010, Happiness and economics: How the economy and institutions affect human well-being, Princeton University Press, Princeton.

G-8 (Eight Industrialised Countries), 2000, Digital Opportunities Task Force (DOT) Initiative, viewed 03 August 2015, from http://www.dotforce.org

Ganju, K.K., Pavlou, P.A. \& Banker, R.D., 2016, 'Does information and communication technology lead to the well-being of nations? A country-level empirical investigation', MIS Quarterly 40(2), 417-430.

Gauteng City-Region Observatory (GCRO), 2013 Quality of Life (QoL) Survey (dataset), Global Print, Johannesburg. 
Geospace International prepared for the GCRO, 2014, Field report: GCRO third quality of life survey, |Global Print, Johannesburg.

Graham, C., 2009, Happiness around the world, Oxford University Press, Oxford.

Graham, C. \& Nikolova, M., 2013, 'Does access to information technology make people happier? Insights from well-being surveys from around the world', The Journal of Socio-Economics 44, 126-139. https://doi.org/10.1016/j.socec 2013.02.025

Greyling, T., 2015, 'An analysis of the quality of life of migrants in Gauteng, a province of South Africa', Journal of Economic and Financial Sciences 8(2), 495-571.

Greyling, T. \& Tregenna, F., 2016, 'Construction and analysis of a composite quality of life index for a region of South Africa', Social Indicators Research 131(3), 887-930.

Gross, E.F., Juvonen, J. \& Gable, S.L., 2002, 'Internet use and well-being in adolescence', Journal of Social Issues 58(1), 75-90. https://doi.org/10.1111/15404560.00249

Helliwell, J.F., 2003, 'How's life? Combining individual and national variables to explain subjective well-being', Economic Modelling 20(2), 331-360. https://doi.org/ 10.1016/S0264-9993(02)00057-3

IHS Regional Economic Explore, 2014, IHS's Regional Economic Focus (REF), viewed n.d., from http://www.ihsglobalinsight.co.za/

International Federation of Information Processing, 2003, World IT Forum (WITFOR), viewed 03 August 2015, from http://www.witfor.org

Kavetsos, G. \& Koutroumpis, P., 2011, 'Technological affluence and subjective wellbeing', Journal of Economic Psychology 32(5), 742-753. https://doi.org/10.1016/j. joep.2011.05.004

Li, S.M. \& Chung, T.M., 2006, 'Internet function and Internet addictive behavior', Computers in Human Behavior 22(6), 1067-1071. https://doi.org/10.1016/j. chb.2004.03.030

Mackerron, G., 2012, 'Happiness economics from 35000 feet', Journal of Economic Surveys 26(4), 705-735.

Maslow, A.H., 1943, 'A theory of human motivation', Psychological Review 50(4), 370-396. https://doi.org/10.1037/h0054346

Mitchell, M.E., Lebow, J.R., Uribe, R., Grathouse, H. \& Shoger, W., 2011, 'Internet use, happiness, social support and introversion: A more fine grained analysis of person variables and internet activity', Computers in Human Behavior 27(5), 1857-1861. https://doi.org/10.1016/j.chb.2011.04.008

Muusses, L.D., Finkenauer, C., Kerkhof, P. \& Billedo, C.J., 2014, 'A longitudinal study of the association between compulsive Internet use and wellbeing', Computers in Human Behavior 36, 21-28. https://doi.org/10.1016/j.chb.2014.03.035

National Planning Commission, 2012, National development plan, viewed 13 July 2015, from http://www.poa.gov.za/news/Documents/NPC\%20National\%20 2015 , from http://www.poa.gov.za/news/Documents/NP
Development $\% 20$ Plan\%20Vision\%202030\%20-lo-res.pdf

Nie, P., Sousa-Poza, A. \& Nimrod, G., 2017, 'Internet use and subjective well-being in China', Social Indicators Research 132(1), 489-516. https://doi.org/10.1007/ s11205-015-1227-8

Organisation for Economic Co-operation and Development (OECD), 2008, Handbook on constructing composite indicators: Methodology and user guide, OECD Publishing, Paris.

Pénard, T., Poussing, N. \& Suire, R., 2013, 'Does the Internet make people happier?', The Journal of Socio-Economics 46, 105-116. https://doi.org/10.1016/j.socec. 2013.08.004

Pierewan, A.C. \& Tampubolon, G., 2014, 'Internet use and well-being before and during the crisis in Europe', Social Indicators Research 119(2), 647-662. https:// doi.org/10.1007/s11205-013-0535-0
Posel, D.R. \& Casale, D.M., 2011, 'Relative standing and subjective well-being in South Africa: The role of perceptions, expectations and income mobility', Social Indicators Research 104(2), 195-223. https://doi.org/10.1007/s11205-010-9740-2

RSA, 2005, Electronic Communications Act. Volume Act No. 36 of 2005, Government Gazette, Pretoria, viewed n.d., from https://www.greengazette.co.za/ search?q="electronic\%20communications $\% 20$ act"

RSA, 2011, National development plan, Government Gazette, Pretoria.

RSA: Department of Communications, 2013, South Africa connect: Creating opportunities and ensuring inclusion in South Africa, South Africa's Broad Band Policy, viewed n.d., from file:///C:/Users/talitag/Downloads/gazette $\% 20$ version $\% 201 \% 20 \% 20$ bb $\% 20$ policy $\% 20 \% 204 \% 20$ dec.pdf

Sabatini, F. \& Sarracino, F., 2014, Online networks and subjective well-being, viewed 13 November 2016, from https://arxiv.org/abs/1408.3550

Sey, A., Coward, C., Bar, F., Sciadas, G., Rothschild, C. \& Koepke, L., 2013, Connecting people for development: Why public access ICTs matter, Technology \& Social Change Group, Seattle.

Stallings, M.C., Dunham, C.C., Gatz, C.C. \& Baker, L.A., 1997, 'Relationships among life events and psychological well-being: More evidence for a two-factor theory of well-being', Journal of Applied Gerontology 16(1), 104-119.

Statistics South Africa, 2015a, An exploration of household survey evidence on skills development and unemployment between 1994 and 2014, viewed 21 October 2015, from http://www.statssa.gov.za/presentation/Stats $\% 20 S A \% 20$ presentation $\% 20$ on $\% 20$ skills $\% 20$ and $\% 20$ unemployment_16\%20September.pdf

Statistics South Africa, 2015b, Mid-year population estimates: P0302, viewed 11 September 2016, from https://www.statssa.gov.za/publications/P0302/ P03022015.pdf

Statistics South Africa, 2015c, National and provincial labour market: Youth Q1: 2008 to Q1: 2014, viewed 28 September 2016, from http://www.statssa.gov. $\mathrm{za} / \mathrm{p} \mathrm{p}=2746$

United Nations, 2001a, United Nations Information and Communication Technology Task Force, viewed 10 August 2015, from http://www.un.org/webcast/ict/ programme.htm

United Nations, 2001b, Human development report 2001: Making new technologies work for human development, Oxford University Press, New York.

Van der Berg, S., 2011, 'Current poverty and income distribution in the context of South African history', Economic History of Developing Regions 26(1), 120-140. https://doi.org/10.1080/20780389.2011.583018

Verme, P., 2009, 'Happiness, freedom and control', Journal of Economic Behavior \& Organization 71(2), 146-161. https://doi.org/10.1016/j.jebo.2009.04.008

Wickramasinghe, C. \& Ahmad, N., 2013, 'Influence of internet usage on social and subjective well-being of Sri Lankan GLIS', The Journal of Happiness \& Well-Being $1(2), 70-84$.

Wilson, W.R., 1967, 'Correlates of avowed happiness', Psychological Bulletin 67(4), 294-306.

Witter, R.A., Okun, M.A., Stock, W.A. \& Haring, M.J., 1994, 'Education and subjective well-being: A meta-analysis', Educational Evaluation and Policy Analysis 6(2), 165-173. https://doi.org/10.3102/01623737006002165

Wooldridge, J.M., 2010, Econometric analysis of cross section and panel data, MIT Press, Cambridge, MA.

World Bank, 2016, World development report 2016: Digital dividends, 1st edn., World Bank, Washington DC. https://doi.org/10.1596/978-1-4648-0671-1

World Economic Forum, 2002, Annual report on the global digital divide initiative, viewed 03 August 2015, from http://www.weforum.org/pdf/Initiatives/Digital Divide_Report_2001_2002.pdf 


\section{Appendix 1}

TABLE 1-A1: Estimation results for subjective well-being with 'Internet home'

\begin{tabular}{|c|c|c|c|c|c|c|}
\hline \multirow[t]{2}{*}{ Regressors } & \multicolumn{2}{|c|}{ Ordered probit } & \multicolumn{2}{|c|}{ OLS } & \multicolumn{2}{|c|}{ IV } \\
\hline & Coefficient & Standard error & Coefficient & Standard error & Coefficient & Standard error \\
\hline Gender & $-0.047 * *$ & 0.015 & $-0.035 * *$ & 0.012 & $-0.039 * * *$ & 0.012 \\
\hline Marital status & 0.0349 & 0.018 & $0.0314 *$ & 0.014 & 0.0349 & 0.018 \\
\hline Employment & $0.0799 * * *$ & 0.016 & $0.0731 * * *$ & 0.012 & $0.063 * * *$ & 0.013 \\
\hline Health & 0.0231 & 0.038 & 0.0246 & 0.030 & 0.0293 & 0.033 \\
\hline Race: mixed race people & 0.0525 & 0.032 & 0.0428 & 0.025 & 0.0153 & 0.023 \\
\hline Race: white people & $0.188 * * *$ & 0.027 & $0.122 * * *$ & 0.021 & $0.067 * * *$ & 0.019 \\
\hline Education level & $0.0139 * * *$ & 0.003 & $0.0102 * * *$ & 0.002 & $0.006 * *$ & 0.002 \\
\hline Satisfaction with money & $0.271 * * *$ & 0.007 & $0.211 * * *$ & 0.005 & $0.206 * * *$ & 0.005 \\
\hline Income & $0.0129 * * *$ & 0.001 & $0.0115 * * *$ & 0.001 & $0.013 * * *$ & 0.001 \\
\hline Age & $-0.0108 * * *$ & 0.003 & $-0.00752 * * *$ & 0.002 & $-0.007 * * *$ & 0.002 \\
\hline $\mathrm{Age}^{2}$ & $0.0002 * * *$ & 0.000 & $0.0001 * * *$ & 0.000 & $0.0001 * * *$ & 0.000 \\
\hline Social relationships & $0.293 * * *$ & 0.010 & $0.227 * * *$ & 0.008 & $0.227 * * *$ & 0.009 \\
\hline Religion & $-0.0419 * *$ & 0.015 & -0.0222 & 0.012 & $-0.030 *$ & 0.012 \\
\hline Internet home & $0.120 * * *$ & 0.021 & $0.082 * * *$ & 0.016 & $0.274 * * *$ & 0.032 \\
\hline Constant & - & - & $1.910 * * *$ & 0.058 & $1.910 * * *$ & 0.058 \\
\hline Cut1 constant & 0.0314 & 0.074 & - & - & - & - \\
\hline Cut 2 constant & $1.133^{* * *}$ & 0.074 & - & - & - & - \\
\hline Cut3 constant & $1.480 * * *$ & 0.074 & - & - & - & - \\
\hline Cut4 constant & $3.638 * * *$ & 0.077 & - & - & - & - \\
\hline$N$ & - & - & - & - & - & - \\
\hline Adjusted or pseudo- $R^{2}$ & - & - & 0.142 & - & - & - \\
\hline Significance & - & - & - & - & - & - \\
\hline
\end{tabular}

OLS, making use of probit- ordinary least square; IV, instrumental variable regression

Note: All models are estimated using robust standard errors to address heteroscedasticity. In IVR, 'laptop' is used to instrument Internet accessed.

$*, p<0.05 ; * *, p<0.01 ; * * *, p<0.001$. Standard errors are in parenthesis. 